\title{
Politeness in the Use of Language in Social Media
}

\author{
Oktiva Herry Chandra ${ }^{1}$ \\ ${ }^{1}$ Department of Linguistics, Faculty of Humanities, Diponegoro University, Semarang - Indonesia
}

\begin{abstract}
The use of social media in communication changes the way people express the idea represented through their language. This study aims to seek for the form of communication patterns in social media and to reveal causes of specific pattern language usage found in media, especially in office domain. The study was conducted using descriptive qualitative by describing the results of observations, interviews, and documentation. The data were collected by non-participatory observation method and note taking technique. Based on the results of the analysis of the data, it can be concluded that the communication patterns are realized in the form of: (1) various forms of language which do not meet the standard language, (2) the use of other non-verbal representations, such as emoticon, and (3) ecrononciation, that is, writing the spoken language. The choice of utterances is affected by relative status, social distance and range of imposition. As communicating to others, most utterances represent the obedience to politeness maxim, namely be friendly (sumanak), be considerate (tepa slira), suitable topic to event (empan papan), and pleasant voice true and good temper (nuju prana).
\end{abstract}

\section{Introduction}

Media social, nowadays, is considered the most effective way of communication since people may have communication with others at any time. This information technology-based media covers various types of communication goals. People use this media to promote programs, shape public opinion, broadcast important events, publicise particularly political issues, and accommodate interpersonal affairs among members of the specific group openly. Social media is also used for discussing current issues that are related to the environment and culture.

[1] included Facebook, tweeter, and WhatsApp into the communication category. The rest are classified into collaboration and multimedia. Each type has its characteristics and restriction. This restriction automatically gives impact the way people communicate with others. These various social media often combine communication to adjust the need of users and provide safety and comfort.

As one of the communication categories, WhatsApp is famous among those who want to have interpersonal communication. The members come from people who have equivalent interests and usually they know well each other. The group works under the management of one or more persons. Compared to other kinds of social media, the content of news or information is usually based on the agreement of its members. There is an internal mechanism among members as a violation occurs during the transaction of messages.

corresponding author : herrychandra67@gmail.com 
This regular communication represents the obedience of group members to values they believe as their cultural elements. The transaction of messages among participants follows the pattern of daily or face to face conversation. Even though they do not have face to face communication, each of them treats their counterparts as if they are engaged in real conversation. The representation of meaning is articulated in various codes of language; acronym, ellipses, phrase, clause and sentences. From the perspective of functionalism, the various forms of language used are the manifestation of language function and part of communication strategies. People may use different forms of language to serve one function.

Different forms of language use in WhatsApp chatting do not mean that the participants apply inappropriate expression or break the principles of using language in honest communication. Beyond them, there must be reasons for choosing this language usage. This article aims to determine the principles that make people choose the given expression in a conversation written on social media. This objective takes a different point of view as conducted by some researchers, namely [2], who focused her research on figuring out the classification of social media based on meaning and of form; [3] gave her attention to the impact of social media to the new language varieties. She found various linguistic changes, such as abbreviation, morphophonology, zeroisation, onomatopoeia, and ellipsis. She also mentioned in her findings the use of emoticons, stickers and memes as media for constructing the self-identity of social media users.

\section{Methodologies}

This research is qualitative. The data as the focused study are gotten from a conversation among participants using social media. The domain of data is a conversation among lecturers and administrative staff at the Faculty of Humanities, University of Diponegoro. This domain provides transportation of messages and information among the members of the faculty. The topics vary from very personal to official topics. Non-participatory observation method was done to collect the data. This is followed by two other techniques, namely recording and note-taking techniques. The data, then, are processed by classifying and grouping them. The data are classified based on three factors affecting the utterances produced by speakers and listeners, namely power, social distance, and range of position. The way of speakers gives utterances to the listener are also analyzed from the viewpoint of politeness strategies. The interpretation is made to the result of analysis, and at this stage, the researcher also concludes.

\section{Theoretical Framework}

WhatsApp is media for communicating interpersonal affairs among the members of a selected group. The pattern of communication is usually adjusted to the need for information and is written in a simple expression containing participants' intentions. [4] Stated that a conversation goes well as each participant gives maximal contribution and obeys the goal and direction of the conversation. He formulated this principle in four maxims, namely quantity, quality, relevance, and manner. In honest communication, people may use all principles and may disobey one or two principals at once. This occurs as participants want to meet the politeness principle [5].

[6] Mentioned that politeness principles relate to the concept of face. In their view, speakers have a responsibility to give respect to one's self-image or face. They proposed two kinds of face, namely positive and negative face. Cheerful face refers to the need for people to be treated well by respecting all aspects that belong to them. Meanwhile, negative face refers to the need of being accessible by letting them do something. A speech is considered polite as it makes the counterpart feel comfortable and safe. The evaluation of the quality of politeness lies on the listeners. 
The speech given in a conversation can make others feel uncomfortable since sometimes the content or the way of delivering speeches is not in agreement with the need of listeners. In this case, speakers usually will take some strategies to minimize the potential of making their counterparts feel uncomfortable. [6] Mentioned that speakers give the speech in several strategies. As the situation is acceptable, speakers give the speech by using on record strategy and off-record strategy. On record, strategy is manifested in two different ways, namely bald on record and facesaving act. Face saving act is done using positive politeness and negative politeness.

Communication in WhatsApp is done in many ways. People use direct ways meaning that the speaker's intention is similar to the meaning of the words in an utterance. People tend to use indirect ways in other conditions since they want to avoid being impolite to their counterparts.

\section{Finding and Discussion}

This section gives a description of the result and discussion as the answer to research questions. The discussion covers 1) the strategy used by speakers as they have to choose the appropriate utterances in a speech event, 2) factors influencing the use of various types of utterances that are adjusted to the need of communication, and 3) politeness strategies used by speakers and listeners as they get involved in a speech event.

\subsection{Strategy Used by Speakers as Producing Appropriate Utterance}

Considering the academic atmosphere of the communication, mainly the speakers want to make their speeches easily understood. Strategy bold on record is preferred over off the record. In this type of speech, speakers use utterances, denoting that the mood of utterances represents the speaker's intention. The forms reveal the function of utterance. The utterances are understood easily as they often contain performative verbs that represent the intention of the speakers. The concise messages are characterizing this type of communication mark this strategy. These are usually carried out as the persons with more power deliver the utterances to less powerful individuals or as the speakers consider the person they are talking to has close relation with them.

The second strategy is using positive politeness in which the participants of communication try to minimize the potential of their speeches to make their listeners feel uncomfortable. The speakers carry out this strategy since they think their speech potentially has a terrible impact on the cheerful face of the listener. The utterances of this strategy at least consist of two parts, namely utterances for reducing the potential of face-threatening and utterances revealing face-threatening face to listeners. The speakers use three strategies to reduce threatening face acts: claiming common ground, showing speaker and listener cooperate for the same reason, and fulfilling the listener's interest.

The third strategy is redressive action which is implemented through negative politeness. Like a positive strategy, negative politeness is used to minimize the threatening act on the listener's face. Some utterances produced by the lecturers and administrative staff obey some strategies, such as stating indirect utterances, giving hedges to utterances, expressing deference utterances, avoiding first and second pronouns, stating FTA as a common interest, and apologizing.

The last strategy is off the record. This strategy is used as the speaker thinks that it is better not to state the intention directly. In other words, the speaker lets the listener interpret the utterance himself/herself. This means the speakers are not engaged in interpreting the utterances. There are some strategies carried out in the conversation. Some of them make over-generalized utterances, displacing the hearer and uttering ellipsis, leaving some items in utterances. 


\subsection{Factors Influencing the Utterances}

The factor that gives influence the form of utterances is the participant in the conversation. Based on the result analysis, two factors contribute to the expression of utterances, namely power and close relation between speaker and listener [7]. As the speaker's power is higher, and the relationship is not close, the utterances made are bald on record, meaning that the speakers use direct speech, in which the utterances are more superficial in form. Ellipsis is often found in this type of conversation. Meanwhile, the listener will make redressive utterances to show respect to the speakers. Positive and negative strategies accompany the listeners' utterances. Since the listener is lower than the speaker, the utterances use phrases or clauses that may show respect and minimize the potential of doing face-threatening acts.

As the speaker is higher and the relation is close, both the speaker and listener tend to use direct speech. The use of complete sentences indicates the utterances. Redressive utterances sometimes are also found since each of them realizes they have to show respect.

The data also show different types of relations where the speaker is not robust and the relationship is close. In this type of participant, the utterances they produce seem very simple. Ellipsis is another characteristic of the conversation. Shortened phrases are also used, and emoticons are the other ways of expressing their intention. In this type of relation, mutual understanding is the basic principle of conversation, even in the simplest form of language expression.

\subsection{Politeness Strategies Used by Speakers and Listeners}

Based on the modification of utterance, the politeness strategy found in social media conversation is expressed through internal and external modification [8]. The internal modification can be seen from the syntactical softener, words and phrases, and intensifier. At the same time, the external modification includes the use of compliments, reasoning, and promise.

The use of interrogative sentences identifies syntactical softener. This indicates that the speaker gives freedom to the listener to decide these appropriate responses to the speech given. Conditional sentences are also found as the strategy to soften the speaker's intention since this sentence also allows listeners to give a response that is appropriate to the need for communication under the listener's willingness. Words and phrases are also used to minimize the face-threatening act. The words please 'tolong' and' forgive me 'maaf' are examples of words or phrases used to soften the utterance [9].

Compliment as external modification makes persons being addressed feel respected, and in turn, he or she will give respond to the intention of the speakers intentionally [10]. Giving reason is also an effort by the speaker to convince the listener that the intention proposed will be responded to appropriately. The reasoning is usually put in the initial position of the utterance. This aims to lead the listener's focus to the softener aspect of the utterance, in addition. Promising is also found as one strategy used by a speaker to soften the face-threatening act.

\section{Conclusion}

Communication in social media, for example, WhatsApp, has its characteristics. The utterances may be delivered in simple expression and or a complete sentence. The use of this language expression is nothing to do with the goodness of the expression rather than meeting the need of conversation. People may be doing something terrible with their speeches during the conversation, meaning they make utterances that threaten their counterparts. 
Considering the potential of making others feel uncomfortable during the conversation, speakers apply some strategies to minimize this potential. The strategies are on record and off the record. The use of on record strategies will be manifested in bald on record and face-saving acts using positive and negative politeness strategies.

The utterances produced by speakers are also influenced by the characteristics of speaker and listener relation. Non-linguistic aspects also play a role in the success of communication. Power, social distance and range of imposition give colour to the pattern of conversation and the elements used in utterances.

In this great opportunity, the writer would like to give his deepest gratitude to the Dean of Humanities Faculty who has provided financial support for conducting this research and also for her support to the final completion of this article. The writer also would like to thank to my friends and students who have dedicated their time for helping the writer in doing the research.

\section{References}

1. A.J Cann, K. Dimitriov and T. Hooley. Social Media: A Guide for Researcher. Research Information Network. Web (2011).

2. Atmawati, Dwi. Penggunaan Bahasa Pada Media Sosial in International Seminar Prasasti III: Current Research in Linguistics. 2016

3. Junus, Fierenziana Getruida. Variasi Bahasa Dalam Sosial Media: Sebuah Konstruksi Identitas in International Conference on Language, Society and Culture 1, 2015.

4. H. P. Grice. Logic and Conversation in Syntax and Semantics 3: Speech Act edited by Cole and Morgan J.L. New York: Academic Press (1975).

5. G.N Leech. Principles of Pragmatics. London: Longman (1983).

6. P. Brown and S.C Levinson. Politeness: Some Universal in Language Usage.

7. Cambridge: CUP (1987).

8. Gunarwan, Asim. Pragmatik: Teori dan Kajian Nusantara. Jakarta: Penerbit Universitas Atmajaya

9. Trosborg, Anna. Interlanguage Pragmatics: Request, Complaints, and Apologies. New York: Mouton de Gruyter (1994).

10. Cruse. D. Alan. Meaning in Language: An Introduction to Semantics and Pragmatics. Oxford: Oxford University Press (2000).

11. Holmes, Janet. Compliment and Compliment Responses in New Zealand English in Anthropological Linguistics 28:458-465, 1986. 